\title{
The South African taX MiX AND ECONOMIC GROWTH*
}

\author{
A H de Wet ${ }^{1}$ \\ Tax Policy Unit, National Treasury \\ N J Schoeman ${ }^{2}$ and S F Koch ${ }^{3}$ \\ Department of Economics, University of Pretoria
}

\begin{abstract}
The research reported in this paper suggests that government fiscal policy can influence economic growth through alterations in the tax mix and the overall size of government spending. The authors estimate the impact on economic growth of changes in fiscal policy via government expenditure, direct taxation and indirect taxation. The results show that economic growth is negatively affected by increases in the size of government, as reflected in its expenditures and direct tax revenues, although significant indirect tax effects are not found.
\end{abstract}

JEL H23, 24, 30

\section{1}

\section{Introduction and background}

The role of government in the economy has always been a hotly debated issue in economic theory. From a policy perspective, an important aspect of this debate in developing countries is the trade-off that society faces between direct and indirect taxes. A fundamental question is whether or not the mix between direct and indirect taxes can be linked to optimum growth and prosperity. Faced with a fixed tax burden, a restructuring of the direct to indirect tax ratio will most certainly change effective income and consumer prices, affecting consumer behaviour, and ultimately altering income distribution and demand levels. It is, therefore, essential that the optimal tax mix be determined for the South African economy.

Based on two-sector models proposed by Feder (1983) and Odedokun (1999), which assess the relationship between the export and real sectors, and monetary and real sectors, respectively, we develop a model to address the relationship between growth and taxes. The study, therefore, makes a contribution to the literature through the development of a direct growth accounting measure of the relationship between taxes and growth while providing initial empirical results based on the developed methodology.

The research results are presented in the following manner. In Section 2, a review of the relevant literature is presented. The empirical model is discussed in Section 3, although the theoretical development of that model is relegated to the Appendix. The data used in the analysis is briefly described in Section 4, while the empirical results of the analysis are presented in Section 5. The research concludes in Section 6, which includes recommendations for further research.

2

\section{Literature review}

The literature surrounding the analysis of government's role in real output and output growth reflects mixed views with regard to the effect of taxes on economic growth.

Empirical evidence by Gerson and Mackenzie (1998) suggests that the impact of tax policy may be undervalued, because of the difficulty in quantifying the way in which it 
alters the behaviour of economic agents. Importantly, tax policy influences the allocation of investment and labour across the sectors of the economy, which may or may not affect the aggregate supply of labour and capital. However, because individuals regard corporations as a shield against the risk of individual debt, revenue-neutral tax shifts from corporations to individuals (and other policies) may encourage saving, investment and growth.

Marsden (1986), using cross section data for 20 countries, regressed the per capita growth rate of GDP on an intercept and the ratio of taxes to GDP and found that a higher tax to GDP ratio correlates negatively with growth. Including the growth rates of domestic investment and employment as independent variables reduced the coefficient of the tax to GDP ratio, although it remains negative. Furthermore, he divided the sample into low and high-income countries finding that the tax to GDP ratio has a significant negative effect on growth rates in low-income countries but that the effect disappears in the high-income country group. Among individual categories of taxes, only domestic taxes on goods and services (and not corporate taxes, personal taxes, or taxes on foreign trade) have a significant negative effect on per capita growth.

The empirical results regarding tax categories presented by Skinner (1988) contradict Marsden's (1986) results. Using data for SubSahara African countries for the period 19651982, Skinner (1988) found that only corporate and personal income taxes significantly and negatively affect output growth, with import and export taxes and, especially, sales taxes having only a marginal effect on output growth. However, import and export taxes together with corporate taxes do have a significant and negative effect on the share of private investment in GDP.

Skinner's analysis agrees with Easterly and Rebelo's (1993) cross-section analysis, which found that the marginal income tax rate has a significant and negative effect on per capita GDP growth in developing countries. They also found that the income tax, the ratio of domestic taxes to GDP, and the ratio of domestic taxes to consumption and investment have significant negative effects on the ratio of private investment to GDP.

The way in which taxes affect the allocation of resources has been researched extensively. Harberger's superneutrality conjecture has opened discussions as to whether or not a different tax mix could have different growth performance effects. In his seminal paper, Harberger (1964) showed that changes in the composition of direct to indirect taxes do not alter labour supply and investment rates to such an extent as to contribute to higher economic growth rates. Since then, various studies have supported and contradicted his findings.

In an extensive paper, Mendoza et al. (1995) examined the theoretical and empirical relationships between tax policy, investment and growth proposed by Harberger. Their theoretical analysis, based on endogenous growth models with human capital accumulation, highlights the effects of factor income and consumption taxes on growth and investment. In general, they conclude that, theoretically, changes in income taxation have stronger effects on growth than changes in capital income and consumption taxation. However, they caution that the effects of taxation on economic activity depend crucially on the elasticity of labour supply and the tax treatment of the sector producing human capital. Using a panel of 18 OECD countries for the period 1966 to 1990 , their empirical findings showed that tax cuts of 10 percentage points in income taxes increased the investment rate by between 1 to 2 percentage points, while cuts in consumption taxes of similar magnitude have similar but opposite effects on investment. The relationship between tax rates and growth is less apparent. Only when the full time dimension is employed do they observe statistical evidence of the effects of taxes on growth and, even then, the magnitude of the growth effects of tax changes is very small. Therefore, they conclude that substantial changes in the tax structure are necessary to observe growth effects.

More recently, Koch et al. (2004) focussed on the South African economy to bring more evidence to the tax mix argument from a developing country perspective. Using data for the time period 1960-2002 and employing data 
envelopement analysis (DEA) they not only assess the impact of taxes on growth but also the ratio of indirect to direct tax influence on growth performance. Their results showed that, contrary to most theoretical research, an increase in indirect taxation relative to direct taxation reduces economic growth. However, they caution to say that the effect of the tax mix is approximately one-fifth of the effect of the total tax burden, so that a decrease in income tax (although increasing the ratio of indirect to direct tax revenue) would still have positive growth effects. They also argue that the effects of taxation in a developing country may be significantly greater than in developed countries, which necessitates further research within a developing countries context.

As can be seen from the discussion, the research results are diverse but also conflicting in regards to the magnitude of the effect of government tax regimes on economic growth. What is apparent, though, is the fact that although different combinations and magnitudes of taxes affect real activities differently, a definite significant relationship exists between government revenue and real economic activities.

\section{3}

\section{The theoretical model}

Based on the two-sector production function of Feder (1983), Odedokun (1999) also developed a two-sector production function model to evaluate the contribution of the monetary sector to economic growth. While Feder (1983) was concerned with the role of exports on economic growth and, therefore, divided the economy into an export and nonexport sector, the Odedokun model uses the monetary and non-monetary, or real sector, to evaluate the role of the monetary sector on economic growth. Arguing that financial development should contribute to higher economic growth in developing countries, he concluded that his empirical estimates provided "...strong and unambiguous evidence in support of this finding" (Odedukun, 1999: 230).

In our analysis we investigate the relationship between government income and the real sector. We, therefore, use the same methodology as proposed by the above authors, but alter it so that we are able to focus on government revenue activities and the tax mix.

Following Odedokun (1999), we have identified two channels through which the government sector could impact economic growth. Firstly, we investigate the impact of government intervention through revenue collection activities. The second channel is through the allocation of resources, assuming resources employed in the private sector are more productive than similar resources employed in the public sector. Therefore, the implication of the model is that resources could be used more effectively in the private sector.

Following the methods proposed by Feder (1983) (see Appendix A) we developed the following real output growth equation:

$$
\begin{aligned}
& \left.\left.\dot{Y} / Y=\alpha\left(\frac{I}{Y}\right)+\beta \dot{L} / L+\theta_{1}\left[T_{d} / T_{d}\right) *\left(T_{d} / T\right)\right]+\theta_{2}\left[\dot{T}_{i d} / T_{i d}\right) *\left(T_{i d} / T\right)\right] \\
& +\left\{\left(\frac{\delta}{1+\delta}\right)-\theta_{1}\right\} \dot{T}_{d} / T_{d}\left(\frac{T_{d}}{Y}\right)+\left\{\left(\frac{\delta}{1+\delta}\right)-\theta_{2}\right\} \dot{T}_{i d} / T_{i d}\left(\frac{T_{i d}}{Y}\right)
\end{aligned}
$$

The variables used in the analysis are discussed in Table 1. 
Table 1

Definitions of variables used in the empirical analysis

\begin{tabular}{|l|l|}
\hline$\dot{Y} / Y$ & Growth rate of total output (GDP); \\
\hline$I / Y$ & The ratio of fixed capital formation to GDP; \\
\hline$\dot{L} / L$ & The growth rate of the labour force; \\
\hline$\left[\left(\dot{T}_{d} / T_{d}\right) \cdot\left(T_{d} / T\right)\right]$ & The growth rate in the direct tax rate as a share of total taxes; \\
\hline$\left[\left(\dot{T}_{i d} / T_{i d}\right) \cdot\left(T_{i d} / T\right)\right]$ & The growth rate in indirect taxes as a share of total taxes; \\
\hline$\left(\dot{T}_{d} / T_{d}\right) \cdot\left(T_{d} / Y\right)$ & $\begin{array}{l}\text { The growth of direct taxes as a share of total income, which measures the relative } \\
\text { efficiency between direct taxes and the real sector; and }\end{array}$ \\
\hline$\left(\dot{T}_{i d} / T_{i d}\right) \cdot\left(T_{i d} / Y\right)$ & $\begin{array}{l}\text { The growth of indirect taxes as a share of total income, which measures the relative } \\
\text { efficiency between indirect taxes and the real sector. }\end{array}$ \\
\hline
\end{tabular}

Since $\theta_{1}$ and $\theta_{2}$ represent the impact of taxation on the real sector, we can regard this as the external effect of the revenue collection activities on the real sector. Furthermore, if we assume $\theta_{1}$ and $\theta_{2}$ to be constant over the sample period, $[\delta /(1+\delta)]-\theta_{i}$ will also be constant since $\delta$ is constant by definition from equation (A4) in Appendix A. These assumptions result in an estimation equation for the growth rate of output, based upon equation (1).

The estimated value of $\theta_{1}$ and $\theta_{2}$ would, therefore, represent the government's external impact on economic growth. If $\theta_{1}$ and $\theta_{2}$ are significant, public sector revenue collections have an effect on economic growth. The intersectoral efficiency differentials are represented by the coefficients on $\left(\dot{T}_{d} / T_{d}\right) \cdot\left(T_{d} / Y\right)$ and $\left(\dot{T}_{i d} / T_{i d}\right) \cdot\left(T_{i d} / Y\right)$. If either of these coefficients is positive, resources collected by the public sector are used more efficiently by the government than the resources in the rest of the real sector. However, the reverse is only true if the coefficient of $\left(\dot{T}_{d} / T_{d}\right) \cdot\left(T_{d} / Y\right)$ and $\left(\dot{T}_{i d} / T_{i d}\right) \cdot\left(T_{i d} / Y\right)$ are more negative than the coefficient of $\left(\dot{T}_{d} / T_{d}\right) \cdot\left(T_{d} / T\right)$ and $\left(\dot{T}_{i d} / T_{i d}\right) \cdot\left(T_{i d} / T\right)$.

The result follows from equation (A4): for public sector inputs to be less efficient than real sector inputs $\delta<0$, thus $\delta /(1+\delta)<0$ as well. Since the coefficient of $\left(\dot{T}_{d} / T_{d}\right) \cdot\left(T_{d} / Y\right)$ and $\left(\dot{T}_{i d} / T_{i d}\right) \cdot\left(T_{i d} / Y\right)$ is comprised of the differential $[\delta /(1+\delta)]-\theta_{i}$, collections to the public sector would be less efficiently used only with a negative $\left|[\delta /(1+\delta)]-\theta_{i}\right|<\left|\theta_{i}\right|$.

The model, therefore, proposes to estimate the direct effect of tax collections on economic growth, as well as the relative efficiency gains or losses imposed on the economy due to the extraction of resources out of the economy to be used by the government.

\section{4 \\ Data description}

Our model is estimated for the South African economy and was constrained by the relative short and reliable time series data available for employment. The estimations were, therefore, applied only over the time period: 1969 to 2003. All data was obtained from the South African Reserve Bank Quarterly Bulletin. All variables were converted into real terms using the GDP deflator. Growth was not converted into percentages but left as decimals.

All variables in the growth equation are stationary, so that Ordinary Least Squares 
(OLS) estimation does not lead to spurious regression results.

\section{5}

\section{Empirical results}

The South African economy experienced a remarkable change in 1994, due to its re-entry into world markets. Therefore, one would expect that there would be a significant change in economic activities before and after this period. For this reason we included an isolation variable (Dum94) in the estimation equation to capture the new economic environment in which the economy has been operating post 1994 .
Moreover, since our focus is on assessing the role of government revenue activities, we must recognise the fact that government revenue activities are implicitly counter-cyclical and would differ according to the state of the economy. Therefore, as an alternative specification we include in the estimation model a recession variable (Dumrec) recognising the differential effects of revenue collections over the business cycle. Furthermore, since the readmission of the South African economy occurred during a recessionary period in the South African economy, the recession dummy implicitly encompasses the readmission effect.

Table 2

Estimation results (1969-2003)

\begin{tabular}{|c|c|c|}
\hline Dependant variable: & $Y / Y$ & $Y / Y$ \\
\hline$L / L$ & $\begin{array}{l}0.0084^{*} \\
(5.567)\end{array}$ & $\begin{array}{l}0.004^{*} \\
(2.830)\end{array}$ \\
\hline$\frac{I}{Y}$ & $\begin{array}{l}0.072^{*} \\
(2.765)\end{array}$ & $\begin{array}{l}0.193^{*} \\
(6.962)\end{array}$ \\
\hline$\left[\left(T_{d} / T_{d}\right) *\left(T_{d} / T\right)\right]$ & $\begin{array}{l}-0.1648 \\
(-0.573)\end{array}$ & $\begin{array}{l}-0.556^{*} \\
(-1.972)\end{array}$ \\
\hline$\left[\left(T_{i d} / T_{i d}\right) *\left(T_{i d} / T\right)\right]$ & $\begin{array}{l}0.596 \\
(1.429)\end{array}$ & $\begin{array}{c}0.375 \\
(0.903)\end{array}$ \\
\hline$\dot{T}_{d} / T_{d}\left(\frac{T_{d}}{Y}\right)$ & $\begin{array}{c}6.533 \\
(0.039)\end{array}$ & $\begin{array}{l}268.38 \\
\quad(1.633)\end{array}$ \\
\hline$\dot{T}_{i d} / T_{i d}\left(\frac{T_{i d}}{Y}\right)$ & $\begin{array}{c}6.533 \\
(0.039)\end{array}$ & $\begin{array}{r}-205.815 \\
(-0.847)\end{array}$ \\
\hline Dum94 & $\begin{array}{c}0.035^{*} \\
(4.957)\end{array}$ & - \\
\hline Dumrec & - & $\begin{array}{l}-0.033^{*} \\
(-4.856)\end{array}$ \\
\hline$R^{2}$ & 0.62 & 0.62 \\
\hline $\operatorname{Adj} R^{2}$ & 0.54 & 0.54 \\
\hline$J B$ & 0.74 & 0.79 \\
\hline$L M(2)$ & 0.84 & 0.98 \\
\hline White & 12.64 & 8.9 \\
\hline
\end{tabular}

*Indicates significance at a $5 \%$ level 
Our first estimation equation, in the second column, shows that neither direct nor indirect taxes have any direct impact on economic growth. The relative efficiency variables also indicate that no efficiency losses occur due to the extraction of resources out of the real economy. The results suggests that, from a tax perspective, the revenue authorities do not have a direct impact on economic growth. Rather, authorities would have to look to influence economic activities indirectly by stimulating employment and investment opportunities in the economy. In fact the first estimation equation implies that the major determinants of growth are generated from labour growth and investment in capital, which lends support to the neo-classical growth models and further suggests the importance of policies, which improve the market-clearing performance of labour and capital markets. The reintroduction into the world economy has also had a significantly positive effect on economic growth, as can be seen by the coefficient estimated for Dum94.

The second estimation equation, reported in column 3 of Table 2, which also encompasses the first, shows that, statistically, there is a direct channel available to the government in its efforts to influence economic growth through revenue collections policy. The significant and negative coefficient on the direct tax effect indicates that direct tax collection is harmful to economic growth. However, the indirect tax effect remains insignificant. The results are consistent with an economic theory advocating that indirect taxes have less influence on economic activities than direct taxes, due to the fact that direct taxes alter the relative prices within the economy. The result implies that, when faced by a fixed revenue constraint, government would do better by increasing indirect tax collections than by increasing direct taxes. Moreover, by consistently decreasing direct taxes government would be able to increase economic growth. The relative efficiency variables are once again insignificant, implying that there are no efficiency gains or losses associated with the avenue of revenue collections.

The coefficient of the recession variable implies that there is a significant difference in economic activity over the business cycle. It is, therefore, very important that government recognise that revenue collecting activities should be adjusted to the state of the economy.

The labour growth and investment ratio coefficients show the importance of labour and capital for economic growth, regardless of which result is considered. The high investment coefficient, relative to the labour growth coefficient, implies that investment has been more growth enhancing than labour growth over the sample period. Once again, we argue that economic growth could be more favourably influenced by government policies that are investment-promoting. Clearly, the recent improvements in macroeconomic stability represent one channel by which the authorities have undertaken investment-enhancing policies. As with the results from the first estimating equation, although the direct channel of taxes seems limited, taxes will, undoubtedly, be able to induce growth-enhancing economic activities merely by altering relative factor prices. To this extent, our results suggest that tax incentives aimed at increasing economic growth should be focussed on investment activities.

\section{6}

\section{Conclusion}

Based on the two-sector model originally proposed by Feder (1983), we have developed a method to directly estimate the impact that government revenue collection would have on economic growth and the efficiency losses attributed to resources being withdrawn from the real sector.

Our estimation results have indicated that the scope of government to directly influence economic growth through taxes is limited. However, in line with economic theory there is evidence that real output growth is negatively related to direct tax revenue collection but that indirect tax collections have no significant effect. Our results imply that by altering the relative ratio between direct and indirect taxes government may be able to influence economic growth. Specifically, by decreasing the direct 
tax burden, economic growth could increase. Decreasing direct taxes does not necessarily mean that government must decrease the total tax take; rather by substituting direct for indirect taxes, the fiscal authorities would have a lesser impact on relative prices, creating smaller distortions in the economy.

Although our results indicate the importance of investment and labour growth on economic growth over the effects of direct and indirect taxation, it is important to remember that direct and indirect taxes are likely to have important effects on labour demand, labour supply, and investment market equilibriums. Therefore, further research into these questions remains necessary, if there is to be a consensus view of the impact the tax mix may have on economic performance, both in terms of efficiency and economic growth.

\section{Endnotes}

* The research presented in this paper represents the opinions and conclusions of the authors and not the views of the National Treasury or any of its affiliated units.

${ }^{1}$ Primary Contact: Senior economist, Deputy Director: Tax Policy Unit, National Treasury, +27-12-315-5879, albert.dewet@treasury. gov.za

2 Professor of Economics, University of Pretoria, +27-12-420-3455, niek.schoeman@ up.ac.za.

${ }^{3}$ Associate Professor of Economics, Department of Economics, University of Pretoria, +27-12-420-3820, steve.koch@up.ac.za.

${ }^{4}$ Results not presented, but can be obtained on request from the authors.

${ }^{5}$ Importantly, due to the fact that investment is listed as a share of total income, the coefficient is multiplied to a higher average value; the labour growth rate is consistently lower than the share of total income devoted to investment. Therefore, the higher investment coefficient is not due to a difference in measurement.

\section{References}

1 EASTERLY, W. \& REBELO, S. (1993) "Fiscal policy and economic growth: An empirical investigation", Journal of Monetary Economics, 32 (December): 417-58.

2 FEDER, G. (1983) "On exports and economic growth”, Journal of Development Economics, 12: 59-73.

3 FUENTE, A. (1997) "Fiscal policy and growth in OECD”, CEPR Discussion Paper: 1755.

4 GERSON, P. \& MACKENZIES, G. (1998) "The impact of fiscal policy variables on output growth”, IMF Working Paper, 98(1).

5 HARBERGER, A. (1964) "Taxation, resource allocation and welfare", in The Role of Indirect Taxes in the Federal Reserve System (ed.) by the NBER and Brookings Institution, Princeton University Press: Princeton, NJ.

$6 \mathrm{KOCH}, \mathrm{S}$.; SCHOEMAN, N. \& VAN TONDER, J. (2004) "Economic growth and the structure of taxes in South Africa: 1960-2002", Mimeo, University of Pretoria.

7 MARSDEN, K. (1984) "Links between taxes and economic growth, some empirical evidence", World Bank Staff Working Paper: 605.

8 MENDOZA, E., MILESI-FERRETTI, G. \& PATRICK, A. (1995) "Do taxes matter for long run growth?", IMF Working Paper, 95(79).

9 ODEDOKUN, M. (1999) How the size of the monetary sector affects economic growth: Econometric evidence from industrial and developing countries, Journal of Policy Modelling, 21: 213-41.

10 SKINNER, J. (1987) "Taxation and output growth: Evidence from African countries", NBER Working Paper 2335. 


\section{Appendix A \\ Mathematical derivation of estimation equation}

The production function of the government sector depends on the level of capital and labour employed and is given in equation A1:

$G=G\left(L_{G} ; K_{G}\right)$

where $G=$ real output of the government sector;

$\mathrm{L}_{\mathrm{G}}=$ labour employed in the government sector; and

$\mathrm{K}_{\mathrm{G}}=$ capital employed in the government sector.

The output of the private sector, as described in equation A2 do not only depend on the level of capital and labour employed but is also influenced by the level of output from the government sector:

$R=R\left(L_{R} ; K_{R} ; G\right)$

where $\mathrm{R}=$ output of the real sector;

$\mathrm{L}_{\mathrm{R}}=$ labour employed in the private sector;

$\mathrm{K}_{\mathrm{R}}=$ capital employed in the private sector; and

$\mathrm{G}=$ the output level of the government sector.

Both the production functions are assumed to have the normal neo-classical properties and would behave accordingly.

The fact that the model only allows for the above two sectors imply that the following identities must hold:

$$
\begin{aligned}
& Y=G+R \\
& L=L G+L R \\
& K=K G+K R
\end{aligned}
$$

where $Y=$ total output or real GDP;

$L=$ total labour force; and

$K=$ the economy wide capital stock.

If markets were efficient, the ratio of marginal products between the two sectors would be equal. However if there is an inefficiency wedge due to productivity differences that cannot be arbitraged, the wedge can be summarised as:

$\frac{M P L_{G}}{M P L_{R}}=\frac{M P K_{G}}{M P K_{R}}=1+\delta$

where $\mathrm{MPL}=$ the marginal productivity of labour;

MPK = the marginal productivity of capital of the government and private sectors respectively; and

$\delta=$ the parameter for the intersectoral efficiency differential.

A value for $\delta>0$ would indicate that resources is employed more efficiently in the government sector, with the reverse being true for the case where $\delta<0$. A value for $\delta=0$ would indicate that resources employed are equally efficient within the two sectors.

Given the model formulation a differentiation of equations (A1) and (A2) yields:

$$
\begin{aligned}
& G=G_{K} \cdot I_{G}+G_{L} \cdot \dot{L}_{G} \\
& \dot{R}=R_{K} \cdot I_{R}+R L \cdot \dot{L}_{R}+R_{G} \cdot G
\end{aligned}
$$

where $\mathrm{I}_{\mathrm{G}}$. and $\mathrm{I}_{\mathrm{R}}=$ sectoral gross investments $\left(K_{G}\right.$ and $\left.\dot{K}_{R}\right)$;

$\dot{L}_{G}$ and $\dot{L}_{R}=$ the sectoral changes in the labour force;

$\mathrm{R}_{\mathrm{G}}=$ the marginal effect of the government sector on the private sector; and

$\mathrm{G}_{\mathrm{K}}$ and $\mathrm{G}_{\mathrm{L}}=$ the marginal product of capital and labour in the government sector

$\mathrm{R}_{\mathrm{K}}$ and $\mathrm{R}_{\mathrm{L}}=$ the marginal product of capital and labour in the private sector

From the definition of gross domestic product in equation $\mathrm{A} 3$ it follows that:

$$
\dot{Y}=\dot{R}+\dot{G}
$$


Now substituting equations A4 and A5 into A6 yields:

$$
\dot{Y}=\left[G_{K} \cdot\left(I_{G}\right)+G_{L} \cdot(\dot{L})\right]+\left[R_{K} \cdot\left(I_{R}\right)+R_{L} \cdot(\dot{L})+R_{G} \cdot \dot{G}\right]
$$

If total investment $I=I_{R}+I_{G}$ and total growth of labour $\dot{L}=\dot{L}+\dot{L}$, equations A4 and A5 implies that:

$$
R_{K} I_{G}+R_{L} \dot{L}_{G}=\frac{1}{1+\delta}\left(G_{K} I_{G}+G_{L} \dot{L}_{G}\right)+\frac{\dot{G}}{1+\delta}
$$

Substituting equation A8 into equation A7 yields a difference equation for output:

$$
\dot{Y}=R K I+R L \dot{L}+\left(\frac{\delta}{1+\delta}+R_{R}\right) \dot{R}
$$

Now, if there exists a linear relationship in the economy such that the real marginal productivity of labour in a given sector is linear to the average output per labourer in the economy such that:

$$
R_{L}=\beta\left(\frac{Y}{L}\right)
$$

Now, dividing equation $\mathrm{A} 9$ by $\mathrm{Y}$ and by denoting $R_{K}=a$ we arrive at the following growth equation of output:

$$
\dot{Y} / Y=\alpha\left(\frac{1}{Y}\right)+\beta \dot{L} / L+\left\{\left(\frac{\delta}{1+\delta}\right)+R_{k}\right\} \cdot(\dot{G} / G) \cdot(G / Y)
$$

If we assume that the marginal productivities are equal across sectors $(\delta=0)$ and that there are no inter-sectoral externalities $\left(R_{x}=0\right)$ then equation A11 reduces to the neo-classical source of growth equation model.

However, it is unlikely for a developing country that you will not see productivity differentials or externalities between the public and private sectors.

Therefore, suppose that the government sector affect the production of the private sector with constant elasticity i.e.

$$
R=R\left(L_{R} ; K_{R} ; G\right)=G^{\theta} \cdot \varphi\left(K_{R}, L_{n}\right)
$$

where $\theta$ is a parameter. It can be shown that

$$
R_{G}+\theta \cdot(R / G)
$$

and rewriting equation A11

$$
\dot{Y} / Y=\alpha\left(\frac{I}{Y}\right)+\beta \dot{L} / L+\frac{\delta}{1-\delta}+\theta \cdot(R / G)(\dot{G} / G) \cdot(G / Y)
$$

But

$$
\theta \cdot \frac{R}{G}=\theta \cdot \frac{R / Y}{G / Y}=\theta \cdot \frac{[1-(G / Y)]}{(G / Y)}=\frac{\theta}{(G / Y)}-\theta
$$

Therefore by using these results and rearranging equation A14 we arrive at the growth equation:

$$
\dot{Y} / Y=\alpha\left(\frac{1}{Y}\right)+\beta \dot{L} / L+\theta \dot{G} / G+\left\{\left(\frac{\delta}{1+\delta}\right)-\theta\right\} \dot{G} / G\left(\frac{G}{Y}\right)
$$

Now, noting that the South African government has committed itself to a stable deficit ratio and that there has existed a stable and consistent relationship between government expenditure and taxes it is possible to proxy $\mathrm{G}$ with taxes $(T)$ such that: 
210

SAJEMS NS 8 (2005) No 2

$$
G=T=T_{d}+T_{i d}
$$

$$
\begin{aligned}
& \text { and } \\
& \frac{\dot{G}}{G}=\frac{\dot{T}_{d}+\dot{T}_{i d}}{G}
\end{aligned}
$$

where $T_{d}$ and $T_{i d}$ are equal to direct and indirect taxes respectively.

Substituting equation A16 into A15 yields a growth accounting type estimation equation which provides a measurement of the effect of taxes on economic growth

$$
\begin{aligned}
& \dot{Y} / Y=\alpha\left(\frac{I}{Y}\right)+\beta \dot{L} / L+\theta_{1}\left[\left(T_{d} / T_{d}\right)^{*}\left(T_{d} / T\right)\right]+\theta_{2}\left[\left(\dot{T}_{i d} / T_{i d}\right)^{*}\left(T_{i d} / T\right)\right] \\
& +\left\{\left(\frac{\delta}{1+\delta}\right)-\theta_{1}\right\} \dot{T}_{d} / T_{d}\left(\frac{T_{d}}{Y}\right)+\left\{\left(\frac{\delta}{1+\delta}\right)-\theta_{2}\right\} \dot{T}_{i d} / T_{i d}\left(\frac{T_{i d}}{Y}\right)
\end{aligned}
$$

